\title{
Assessing the Current State of Curl Type Improvement for Karakul of Botoşani Breed in Relation to the Color Variety
}

\author{
Ionică NECHIFOR ${ }^{2}$, Marian Al. FLOREA², Constantin PASCAL ${ }^{1,2^{*}}$, \\ ${ }^{1}$ University of Agricultural Sciences and Veterinary Medicine - Faculty of Animal Science, Iaşi, Romania \\ ${ }^{2}$ Agricultural Station of Research and Development for Sheep and Goat Growing Popăuţi - Botoșani \\ *corresponding author: pascalc61@yahoo.com; pascalc@uaiasi.ro
}

Bulletin UASVM Animal Science and Biotechnologies 76(2)/ 2019

Print ISSN 1843-5262; Electronic ISSN 1843-536X

DOI:10.15835/buasvmcn-asb: 0007.19

\begin{abstract}
The curl's form and type has always been an important objective of improving the Karakul of Botoşani sheep because some traits such as length, degree of closure, width and height are reflected in an original way over the general aspect of the pelt, influencing the aesthetic and commercial value of them. In pelt's performance-specific control activities, for quality analysis is insisted mainly on the main traits that influence the expression with a certain type or curl form. In order to create conditions for genetic expression of the desired curl shape, it is necessary to follow the improvement of the following parameters: length, height, width, degree of closure, circumferential direction, contour and layout of the pelt surface curls. The used method in the assessment of the objectives was based on the technical norms specified in Section 1.4 and 1.5 of the MADR Order no. 22 / 20.01.2006, and the statistical processing of the data was based on the use of S.A.V.C. The assessment of the type of curls in long and medium tubes shows a considerable improvement in this character since the type was identified in $65.11 \%$ of cases in 2005 and increased to $66.66 \%$ in 2015. On the respective interval, the proportion of the desired lambs increased by more than $1.5 \%$, the difference being statistically significant for $\mathrm{p}<0.01$. The proportion of lambs where the curl was predominantly of the flattened type and with a low degree of closure, respectively wave or smooth, was kept within relatively constant limits placed around $20 \%$, with relatively reduced variations from one generation to the next.
\end{abstract}

Keywords: pelts, Karakul of Botoşani, curl type

\section{Introduction}

Karakul of Botoşani was formed through a controlled cross-breeding process between local Țurcană sheep and Karakul genitors imported from Asian zone in which Karakul breed was formed. In breeding is applied a selection in according with the basic traits of pelts aiming the improvement of colour, fibres quality, loop shape, specific features of loop in ensemble and quality of dermal layers. In addition to the specific characters of fibre that form the curl, the value of a pelt is given even by other fibre characteristics, loops and skin structure. Some of these characters have a major influence on the aesthetic and commercial value of the leather because, by their degree of expression, they define the curl as a morphological unit, but also the shaping, shape and contour described by the arrangement of all surface pelt curls. To highlight the practical importance of these characters, in 1996 Taftă et al. states that all these attributes have a great influence on the quality of the curls because "they have repercussions in a 
Table 1. Average score obtained in appreciating of curl type in relation to colour variety

\begin{tabular}{cccccccc}
\hline Colour variety & $\mathrm{n}$ & $\bar{X}$ & $\pm \mathrm{s} \bar{x}$ & $\mathrm{~s}$ & $\mathrm{~V} \%$ & Minim & Maxim \\
\hline Black & 1501 & 99.26 & 0.831 & 18.166 & 18.302 & 58 & 135 \\
\hline Greyish & 1181 & 84.45 & 0.468 & 16.073 & 19.031 & 58 & 135 \\
\hline Brown & 428 & 81.67 & 0.762 & 15.774 & 19.315 & 63 & 128 \\
\hline Pink & 103 & 84.40 & 1.831 & 18.588 & 22.024 & 40 & 128 \\
\hline Grey & 530 & 87.27 & 0.784 & 18.051 & 20.684 & 63 & 128 \\
\hline
\end{tabular}

certain way even on the commercial aspect of the curl". Therefore, the sheep's growth and selection for the production of pelts, shape and type of curl is given special attention being considered as the main objectives for improvement of Karakul sheep. The practical importance of assessing the specific character of the curls is also evidenced by the fact that, based on the selection applied for this character in Namibia, a new type of Karakul sheep has emerged, in which the curl is easily dismantled, flattened, and by arrangement generates, predominantly, sinuous and flat patterns, with intense luster (Schoeman et al., 1992).

\section{Materials and methods}

The biological material subjected to appreciation was represented by pure Karakul of Botoşani lambs belonging to all varieties of colour obtained on an interval of three successive generations, coming from the breeding seasons of years 2013, 2014 and 2015. Biological material was represented by lambs belonging to colour varieties formed inside the breed. The entire flock of sheep and lambs is over 95\% in private farms located in the breeding area (North-Eastern part of Romania) and only 5\% is in Agricultural Station of Research and Development for Sheep and Goat Growing Popăuţi-Botoşani.

The method applied in assessing the objectives was based on the technical rules specified in Section 1.4 and 1.5 of the MADR Order no. 22/20.01.2006, published in the Official Gazette of Romania no. 146 from 15.02 .2006 in which are specifying the aspects of how the production of pelts official control is carried out. All the lambs obtained have been appreciated by planed evaluations in their first two days after birth. The data obtained were compared with those obtained in the performance control of first-generation of lambs obtained since the founding of the Genealogical Register of the Karakul of Botoşani breed, respectively the lamb generation from 2005. The statistical processing of the data was based on the use of S.A.V.C. (Statistics Analysis of Variance and Covariant, 2003). In order to test the statistical significance of the differences between the averages of the values of the studied parameters and the correlations between them, the variables analysis (ANOVA Single Factor) and Pearson Correlation, were used, both included in the used software.

\section{Results and discussion}

When evaluating the pelt quality, greater attention is paid to the curl's length and width dimensions, butalso to the way they are positioned. The explanation of this situation is that the length is also a criterion for the classification of the curl in tube-shaped curl (12-30 mm) or in the form of beans (5-12 $\mathrm{mm})$.

Regarding the curl uniformity, in many specialized publications, it is shown that on the surface of a pelt, the curls are usually of different length. Typically, the length is larger for curls placed on the crotch and has lower values than those on the top of the withers. Also, the length of curls is reduced from those placed on the upper line to those in the abdominal area (Pascal 2007, Pascal 2015, Taftă 1983, Taftă 1967).

From the point of view of the breeder, the major objective is to obtain pelts where over $75 \%$ of all curls have approximately the same dimensions for length, width and height (Pascal et al., 2011, Nechifor et al., 2015, Nechifor et al., 2014, Nechifor 2017). This was the reason why these researches were organized. The diagram described in the graphical representation of the colour varieties distribution by type of curl reveals that the breeding process is at different levels in the five analyzed varieties (Table 1 and Fig. 1).

When assessing this character in the black lamb variety, it is found that the dominating curls have the tube shape (Table 1 ) and the improvement process is more advanced. The analysis of the obtained results revealed that out of the total of 


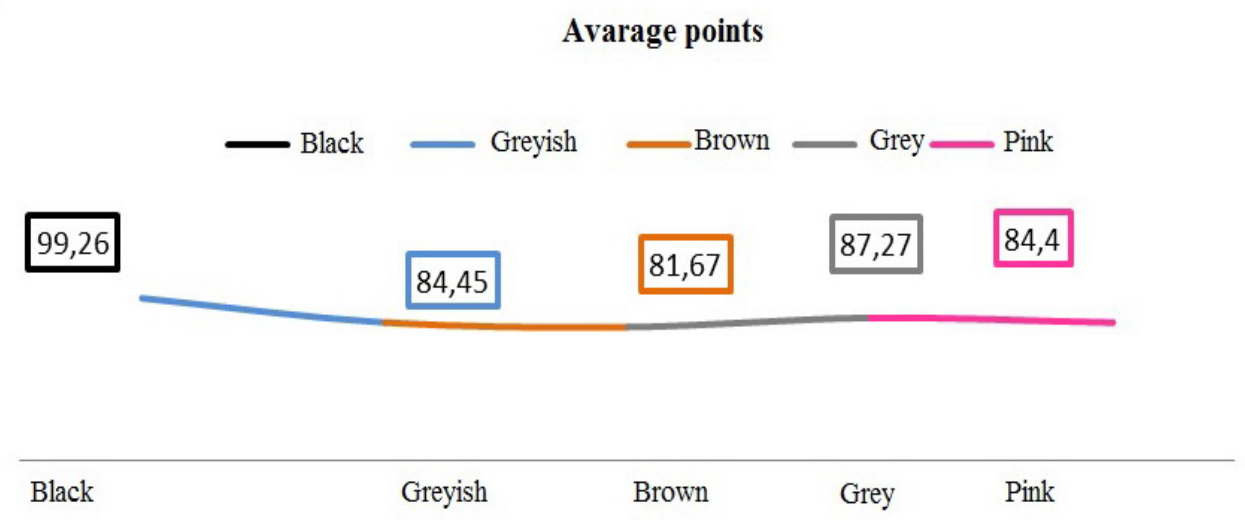

Figure 1. Distribution of herd in relation to average score obtained for curl type (\%)

Table 2. Frequency of curls type for varieties of Karakul of Botoşani breed

\begin{tabular}{|c|c|c|c|c|c|c|c|c|c|}
\hline \multirow{3}{*}{ Colour variety } & \multirow{3}{*}{ Curls shape } & \multicolumn{8}{|c|}{ Frequency on evaluation season } \\
\hline & & \multicolumn{2}{|c|}{2005} & \multicolumn{2}{|c|}{2013} & \multicolumn{2}{|c|}{2014} & \multicolumn{2}{|c|}{2015} \\
\hline & & $\mathrm{n}$ & $\%$ & $\mathrm{n}$ & $\%$ & $\mathrm{n}$ & $\%$ & $\mathrm{n}$ & $\%$ \\
\hline \multirow{5}{*}{ Black } & Long tubes & 295 & 39.28 & 214 & 44.67 & 213 & 38.17 & 221 & 46.92 \\
\hline & Medium tubes & 188 & 25.03 & 131 & 27.35 & 145 & 25.98 & 93 & 19.74 \\
\hline & Short tubes & 105 & 22.29 & 49 & 10.23 & 84 & 15.05 & 61 & 12.95 \\
\hline & Wave with intense luster & 98 & 13.04 & 63 & 13.15 & 110 & 19.71 & 62 & 13.16 \\
\hline & Flattened & 65 & 8.65 & 22 & 4.60 & 6 & 1.09 & 34 & 7.23 \\
\hline \multirow{5}{*}{ Greyish } & Long tubes & 152 & 30.52 & 73 & 18.25 & 85 & 20.48 & 160 & 36.98 \\
\hline & Medium tubes & 135 & 27.15 & 94 & 23.50 & 78 & 18.80 & 145 & 32.19 \\
\hline & Short tubes & 98 & 19.67 & 118 & 29.50 & 122 & 29.40 & 65 & 14.73 \\
\hline & Wave with intense luster & 85 & 17.06 & 115 & 28.75 & 130 & 31.32 & 71 & 16.10 \\
\hline & Flattened & 28 & 11.86 & - & - & - & - & - & - \\
\hline \multirow{5}{*}{ Brown } & Long tubes & 12 & 6.43 & 6 & 4.61 & 7 & 3.62 & 4 & 3.74 \\
\hline & Medium tubes & 38 & 20.32 & 20 & 15.38 & 13 & 6.70 & 9 & 8.41 \\
\hline & Short tubes & 35 & 18.71 & 25 & 19.23 & 45 & 23.19 & 34 & 31.77 \\
\hline & Wave with intense luster & 88 & 47.06 & 79 & 60.78 & 119 & 61.34 & 60 & 56.08 \\
\hline & Flattened & 14 & 7.48 & - & & 10 & 5.15 & - & \\
\hline \multirow{5}{*}{ Grey } & Long tubes & - & - & 12 & 6.70 & 8 & 5.97 & 12 & 6.21 \\
\hline & Medium tubes & - & - & 64 & 35.75 & 37 & 27.63 & 28 & 14.50 \\
\hline & Short tubes & - & - & 34 & 18.99 & 38 & 28.35 & 57 & 29.53 \\
\hline & Wave with intense luster & - & - & 55 & 30.72 & 38 & 28.35 & 85 & 44.07 \\
\hline & Bean type & - & - & 14 & 7.84 & 13 & 9.70 & 11 & 5.69 \\
\hline \multirow{4}{*}{ Pink } & Long tubes & - & - & 3 & 7.14 & - & - & - & - \\
\hline & Medium tubes & - & - & 6 & 14.28 & 6 & 15.78 & - & - \\
\hline & Short tubes & - & - & 9 & 21.42 & 5 & 13.15 & 6 & 23.08 \\
\hline & Wave with intense luster & - & - & 24 & 57.16 & 27 & 71.07 & 20 & 76.92 \\
\hline
\end{tabular}

1501 black lambs evaluated in the three seasons, the average score for the type of curl was higher than 90 points out of 100 possible.

Also based on statistically processed data, it can be noticed that if in 2005 the proportion of black lambs with tubular curl was $86.60 \%$, the average values recorded in 2013 indicate a reduction of their weight to $4.75 \%$ and $7.4 \%$ in 2014 and by 6.99 in the generation of the 2015 season (Table 2).
However, if we analyse the most valuable types of curls, namely those in the form of long and medium tubes, we can say that the improvement of this character is in progress because the proportion of lambs found predominate this type progressively increases from $65.11 \%$ in 2005 to $66.66 \%$ in 2015 . This means an increase in the incidence of lambs with the desired curls, meaning $1.55 \%$ of those with medium and long tubes, the difference being significant for $p<0.01$. Also, the 


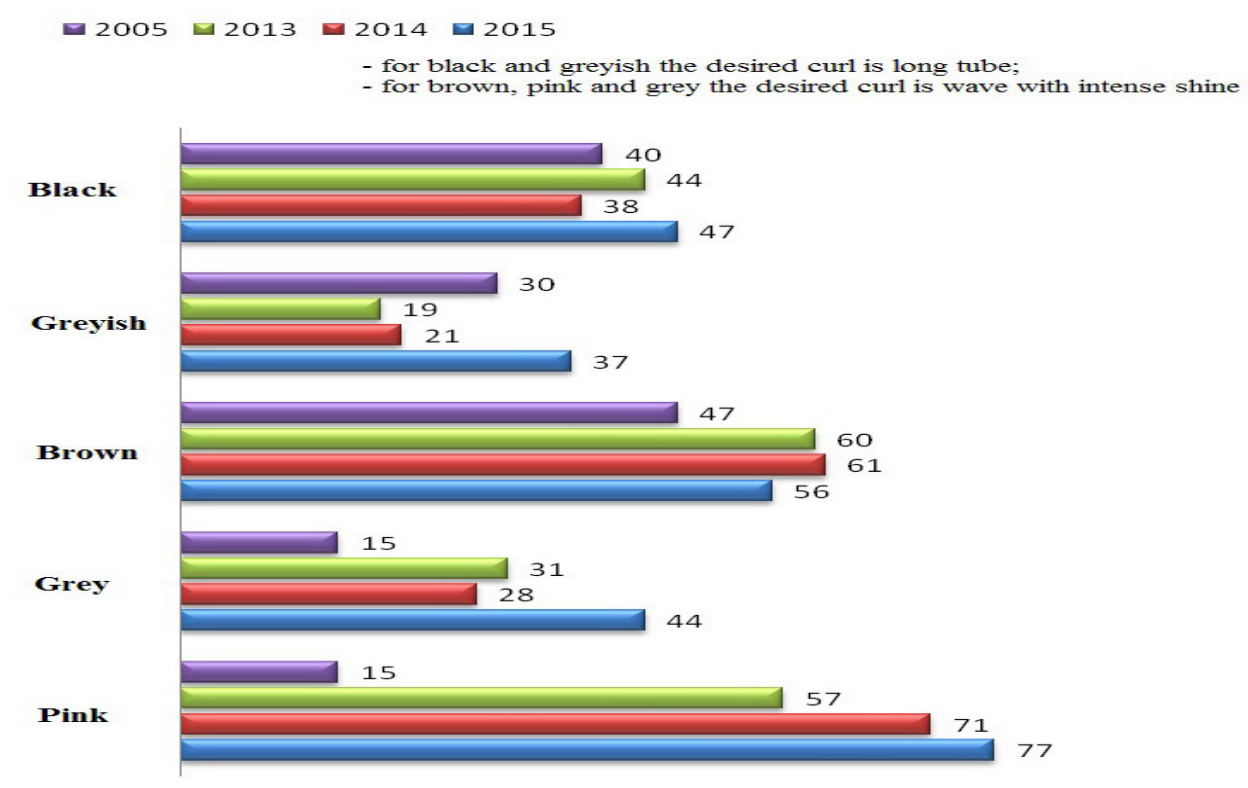

Figure 2. Frequency of desired type of curls in relation to variety of colour (\%)

proportion of lambs that had a flattened curl with a low-wave or flattened flatbed was kept within relatively constant limits of around 20\% with reduced variation from one generation to the next.

Examination of the current level at which the expression of desired curl type is found in relation to the colour variety is synthetically reproduced in figure. 2. For a good interpretation of the data, we have to specify that the type to which the character of the curl type tends to is different for each colour variety. If for black and greyish variety the trend is to increase the uniformity degree of the longer curls, for the coloured varieties, it is desired a increase in the improvement of some objectives which may be the basis of obtaining the curls disposed in the form of low waves with intense luster.

In full agreement with the above mentioned it can be observed that in the 2015 generation, the expression of the desired type of curls was present at approx. $50 \%$ of the lambs belonging to the brown, grey and pink varieties. For the black and greyish the desired curl was identified at a proportion of less than $50 \%$.

Comparing the results, we can conclude that in the coloured varieties the degree of transmission of the desired curl type, the intense luster wave, is higher and the selection according to this character was more efficient.
This conclusion is supported by other results in the literature which show that the selection of lambs with thin pelt and incomplete curl formation has the effect of expressing in the phenotype the predominance of lambs dominated by the type of wave associated with special gloss (Thompson, 1938; Albertyn et al., 1993; Pascal et al., 1994; Schoeman, 1998; Iñiguez et al., 2008). Taking into account all these aspects, but also the average levels of this character, we can say that the improvement is in full progress and in relation to the future trends we can intervene by reorienting the selection process in order to increase the proportion represented by the desired curl type.

In comparison to other values quoted by the literature, the ones obtained converge in sense and intensity of expression. In a study carried out on the black varieties population of the Karakul of Botoşani breed, it is shown that the proportion of those who had a different curl compared to the desired type was $14.5 \%$ for the biological material of breeding line 5 and $11.8 \%$ to those in line 1557 (Marin et al., 1975). In other studies, performed on Karakul of Botoşani lamb population it is stated that "in terms of the shape of the curl, the most frequent are those whose curls have the shape of a tube (34.69\%)" and other curls have a relatively equal proportion placed in the range of $17 \%$ and 21\% (Hrincă et al., 1991). Also in the black variety in 1977, in some studies carried out by Marin, it 
Table 3. The difference and significance of difference for the score obtained in the curl type assessing

\begin{tabular}{ccccc}
\hline Criteria 1 & Criteria 2 & $\begin{array}{c}\text { Difference in } \\
\text { average }\end{array}$ & $\begin{array}{c}\text { Difference } \\
\text { meaning }\end{array}$ & $\begin{array}{c}\text { Significance } \\
\text { threshold }\end{array}$ \\
\hline Grey & Greyish & 2.82 & insignificant & - \\
\hline Grey & Brown & 5.6 & significant & 0.01 \\
\hline Grey & Black & 11.99 & significant & 0.01 \\
\hline Grey & Pink & 2.87 & insignificant & - \\
\hline Pink & Greyish & 0.06 & insignificant & - \\
\hline Pink & Brown & 2.73 & insignificant & - \\
\hline Pink & Black & 14.86 & significant & 0.01 \\
\hline Black & Greyish & 14.8 & significant & 0.01 \\
\hline Black & Brown & 17.59 & significant & 0.01 \\
\hline Brown & Greyish & 2.79 & insignificant & - \\
\hline
\end{tabular}

was found that in the black lambs the proportion of those with tube type and large and medium bobs was $70.20 \%$, and only $20.8 \%$ for short bob and wave.

In the greyish variety, the non-uniformity of the gloss and the modelling led to changing the selection criteria by focusing on those characters that are associated with better uniformity for some shapes and sizes of the curls. Compared to the values obtained in 2005 when they insist on selecting only the pelt with flattened and intense luster wave curls, lately due to the demand for tubular curl, the proportion of lambs that in 2015 had predominantly a curl in the form of long and medium tubes increased by $3.5 \%$, the difference having a high degree of statistical significance for $\mathrm{p}<0.01$.

For the brown colour, the criteria for curl type selection is mainly focused on types that facilitate the expression of genotype in undefined, low-height curls with the longitudinal axis parallel to the surface of the pelt, with slightly loose fibres in the curl. The presence of these characteristics leads to the appearance of wave and flattened curls.

The evaluation done on lambs' shows a progressive increase in the number of individuals dominated by waves with intense luster from $47.06 \%$ to $65.42 \%$ in the generation of 2015 . This was possible because after the homologation of brown variety, this have been able to move on to an increase in criteria that improve the desired curl type. Practically, because the selection difference has high values and a high degree of statistical significance (highly significant for $\mathrm{p}<0.05$ ), the efficiency of the selection is confirmed and, implicitly, the improvement of this character has a confidence level of over $95 \%$.

The grey variety is in the process of genetic consolidation in order to meet the criteria for a subsequent homologation. At grey lambs, in the process of improving the curl type, it is desired that the cylindrical curls or the slightly flattened curls to dominate the genotype, with a welldefined pattern and intense luster.

Based on the research, it was found that the shape of the desired curl holds the highest proportion. An exception is the tube type curl, which holds, in each generation, less than $7 \%$. Starting from this finding it can be stated that the improvement must be intensified in such a way that in each generation the proportion of those who will have a constant size, density and uniformity will increase.

If we consider that the aim of the improvement is to obtain a type of curl with a wave shape and intense luster, we can say that this improvement is on favourable coordinates since the proportion of lambs with such a curl type increases from $30.72 \%$ in 2013 to $44.07 \%$ in 2015 . The difference of nearly $14 \%$ indicates the efficiency of the selection applied to consolidate the curl type desired in new generations.

The pink variety has a small number of active populations that belongs to the category registered in the Genealogical Register of the breed. This variety is in the process of forming, and thanks to the beauty of the pelt, draws a special attention from the breeders. Being a composite colour, uniformity is very difficult to obtain. Also, the curl type registers increased variability and the 
improvement is aimed at promoting the flattened curl type, meaning wave with a special luster.

In the analyzed period lambs with this curl type increase from $57.16 \%$ in 2013 to over $75 \%$ in the 2015 evaluations. These results confirm not only the efficiency of the selection but also the fact that the amelioration is on favourable coordinates. Determination of differences and their significance indicates that for the values obtained in the curl type evaluation, significant differences for $\mathrm{p}<0.01$ are recorded (Table 3).

For the average score obtained from the analysis of this character, there are also insignificant differences (between grey and greyish, between grey and pink, pink and brown and between brown and greyish) usually between the classic and the coloured ones.

\section{Conclusions}

The obtained data at the end of research confirm the fact that at Karakul of Botoşani breed breeding process is in progress and the applied selection for retaining and conducted of reproduction process is efficient.However, by the fact that the desired type of loop is different, respectively tubes at lambs from greyish, black and brown varieties, and wave type at the ones with grey and pink colour, in breeding process the targets are different.In generation of lambs obtained in 2015 the tubular type of curls was present in about $50 \%$ of the lambs belonging to the brown, grey and pink varieties, whereas in the black ones the type was identified in a proportion of less than $50 \%$.

\section{References}

1. Albertyn LR, Schoeman SJ, Groeneveld HT (1993). Factors influencing the quality of Karakul pelts, with emphasis on discrete characteristics. S. Afr. J. Anim. Sci., vol. 23, p. 183

2. Hrincă Gh, Ursu E, Vicovan G, Filote E (1991). Asocierea tipurilor de haemoglobină cu principalele însușiri ale pielicelelor mieilor din rasa Karakul of Botoşani/ Association of haemoglobin type with main features of Karakul of Botoşani breed lambs' pelts. Scientific Papers ICDCOC Palas, vol. VII, p. 49-57
3. Iñiguez L, Mueller J (2008). Characterization of Small Ruminant Breeds in Central Asia and the Caucasus. International Center for Agricultural Research in the Dry Areas (ICARDA), Aleppo, Syria

4. Marin I (1977). Rezultate privind calitatea pielicelelor la metișii $\mathrm{F}_{1}$ Karakul negru x Ţurcană albă/Results regarding pelts quality at half-breed $\mathrm{F}_{1}$ Karakul black x Țurcană white. Scientific Papers ICDCOC Palas, vol. III, p. 245-255

5. Nechifor I (2017). Cercetări privind ameliorarea genetică a rasei Karakul de Botoşani/Research regarding genetic breeding of Karakul of Botoşani breed. PhD thesis, UASVM Iaşi, Romania

6. Nechifor I, Pascal C, Claudia Nechifor (2014). Studies regarding the application effect of productive control techniques on improvement of Karakul lamb pelts quality. Lucrări Știinţifice, Seria Zootehnie, ISSN L 1454-7368, vol. 60, p. 76-81

7. Nechifor I, Pascal C, Florea MA (2015). The colour transmission in the case of cross breed sheep belonging to the black Karakul variety. Bulletin UASVM Animal Science and Biotechnologies, 72(2)/2015, p. 199-202

8. Pascal C (2007). Tehnica aprecierii şi evaluării performanţelor productive la ovine şi caprine/ Technique for appreciation and evaluation of productive performances at sheep and goats. Editura Alfa, Iaşi

9. Pascal C (2011). Researches regarding quality of sheep pelt obtained from Karakul of Botoşani sheep. Biotechnology in Animal Husbandry, Belgrade, ISSN 1450-9156, vol. 27, p. 1123-1131. DOI:10.2298/BAH1103123P

10. Pascal C, Gîlcă I, Creangă Șt, Vintilă V (1994). Cercetări comparative privind unele însuşiri ce influenţează calitatea pielicelelor la mieii de rasă Karakul şi metişi/ Comparative research regarding some features which influence the quality of Karakul breed lambs pelts and half-breeds. Lucrări Ştiinţifice, Seria Zootehnie, vol. 37/38, USAMV Iaşi, p. 216-221

11. Schoeman SJ (1998). Genetic and environmental factors influencing the quality of pelt traits in Karakul sheep. South African Journal Anim. Sci., vol. 28 (3/4), p. 125-139

12. Schoeman SJ, Albertyn JR (1992). Estimates of genetic parameters and genetic trend for fur traits in a Karakul stud flock. S. Afr. J. Anim. Sci., vol. 22, p. 75

13. Taftă V (1967). Creşterea şi ameliorarea oilor Karakul şi metişi/Rearing and breeding of Karakul sheep and halfbreeds. Editura Agrosilvică, București

14. Taftă V (1983). Creşterea şi exploatarea intensivă a ovinelor/Sheep intensive rearing and exploitation. Editura Ceres, București

15. Thompson AD (1938). Karakul sheep - Government flock and the industry in South West Africa. John Meinert, Windhoek. 